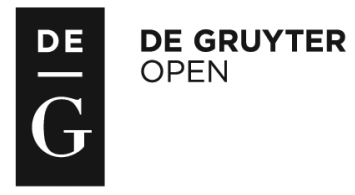

Administration, vol. 65, no. 3 (2017), pp. 123-139

doi: 10.1515/admin-2017-0027

\title{
Poverty proofing - An evolutionary process towards poverty reduction
}

\author{
Helen Johnston* \\ National Economic and Social Council, Ireland
}

\section{Introduction}

Poverty proofing is a way of assessing policies and programmes for their potential or actual impact on people at risk of poverty. In Ireland it was initially introduced in 1998 as part of the implementation of the National Anti-Poverty Strategy (NAPS). It has since evolved through a number of versions and has been reviewed by a number of individuals and organisations (e.g. Johnston \& O'Brien, 2000; NESC, 2001; Office for Social Inclusion, 2006). Following the economic crash in 2008 less institutional attention was given to poverty assessment than in the preceding ten years. The National Action Plan for Social Inclusion 2007-2016 made reference to poverty impact assessment though little actual assessment took place. Memoranda to government, however, still ask about the impact of any policy or programme on poverty, along with gender balance, impact on rural communities, employment, cost to the Exchequer, North-South and East-West relationships, industry costs and quality regulation, and social impact assessments are undertaken on the welfare and income tax measures of annual budgets. In the current programme for government there is reference to poverty proofing, along with rights and equality proofing, where it is stated, 'We will develop the process of budget and policy proofing as a means of advancing equality, reducing poverty and

*The opinions expressed in this paper are the author's own and do not necessarily represent the views of the National Economic and Social Council. 
strengthening economic and social rights' (Government of Ireland, 2016, p. 104).

Nearly twenty years on from its initial introduction it is pertinent to ask to what extent, if any, did poverty proofing raise awareness of the need to design and implement policies to tackle poverty? How was poverty proofing implemented and could this have been done better? What, if anything, worked in poverty proofing and what were its limitations? Did it lead to the development and implementation of policies which resulted in poverty reduction? How should the current commitment in the programme for government to budget and policy proofing as a means of reducing poverty be implemented? This article traces the implementation and review of poverty proofing and attempts to answer some of these questions. The next section discusses the concept of poverty proofing, followed by a section on the introduction of poverty proofing in Ireland. The review and revision of the initial template of poverty proofing are then considered before bringing readers up to date with the current position. The paper concludes by making suggestions on what should be done to meet the commitment in the programme for government.

\section{Concept of poverty proofing}

Poverty proofing has been defined as 'the process by which government departments, local authorities and state agencies assess policies and programmes at design and review stages in relation to the likely impact they will have or have had on poverty and on inequalities likely to lead to poverty with a view to poverty reduction' (Department of Social, Community and Family Affairs, 1998).

Conceptually, it was developed from the idea of social auditing, which had been carried out in South Australia in the 1990s, and from the PAFT (Policy Appraisal and Fair Treatment) initiative in Northern Ireland, which came into effect in 1994. The PAFT guidelines have since been replaced by the Section 75 statutory duties of the Northern Ireland Act, 1998. The Section 75 statutory duties aim to encourage public authorities to address inequalities and demonstrate measurable positive impact on the lives of people experiencing inequalities.

The development of poverty proofing in Ireland can draw some parallels with regulatory impact analysis (RIA), which was developed in 2002 and piloted in five government departments in 2004 before being formally applied across government departments and offices 
(Department of the Taoiseach, 2005). The operation of RIA was reviewed in 2008 by Goggins \& Lauder, who identified a number of shortcomings, including the need for high-level support for RIA, as well as the need for comprehensive guidelines which would provide details on how to calculate costs and benefits, include practical examples and suggest a variety of training options.

These examples from other countries and sectors informed the development and revision of poverty proofing in Ireland.

\section{Introduction of poverty proofing in Ireland}

The Irish NAPS Sharing in Progress was launched in 1997, following two years of analysis and consultation, and contained a commitment to introduce poverty proofing (Government of Ireland, 1997). Consideration was given to how poverty proofing might be developed and it was introduced on a pilot basis in 1998. The key elements of poverty proofing were set out in a framework document, PolicyProofing in the Context of the National Anti-Poverty Strategy, which was prepared by an interdepartmental policy committee in discussion with the social partners (Department of Social, Community and Family Affairs, 1998). Then, following a government decision in July 1998, poverty proofing was included as a requirement in the Cabinet Handbook, which stated that memoranda for government should, inter alia, 'indicate clearly, as appropriate, the impact of the proposal for... persons living in poverty or at risk of falling into poverty, in the case of significant policy proposals' (Johnston \& O'Brien, 2000, p. 65).

The rationale for the introduction of poverty proofing was given as:

a) to act as a tool in the implementation of the strategy, in particular ensuring and subsequently measuring the degree to which the NAPS targets are being achieved;

b) to assist departments to assess the impact of their spending on anti-poverty measures and, if necessary, to refocus their expenditure to meet the NAPS targets;

c) to ensure that policies and programmes do not contribute to greater poverty or inequality;

d) to ensure that potential policies and programmes are developed in a way that benefits people living in poverty, particularly those identified as consistently poor, and prevents others at risk of poverty from falling in to poverty; and 
e) to assist the subsequent monitoring and evaluation of the strategy. (NESC, 2001, pp. 3-4)

The poverty proofing guidelines (Department of Social, Community and Family Affairs, 1998) stated that poverty proofing was to take place in the following circumstances:

- the preparation of departmental statements of strategy and annual business plans;

- designing policies and preparing memoranda to government on significant policy proposals;

- the preparation of the estimates and annual budget proposals, which also includes expenditure reviews and programme evaluations;

- the preparation of the National Development Plan and other relevant EU plans and programmes; and

- the preparation of legislation.

The guidelines went on to spell out how poverty proofing should be carried out by answering the following set of questions:

- What is the primary objective of this policy/programme/ expenditure proposal?

- Does it:

(i) help to prevent people falling into poverty?

(ii) reduce the level (in terms of numbers and depth) of poverty?

(iii) ameliorate the effects of poverty?

(iv) have no effect on poverty?

(v) increase poverty?

(vi) contribute to the achievement of the NAPS targets?

(vii) address inequalities which might lead to poverty?

(viii) reach the target groups?

- What is the rationale and basis of the assessment (for example, administrative data sources, household survey data, working group or task force reports) behind each of these replies?

- If the proposal has the effect of increasing the level of poverty, what options might be identified to ameliorate this effect?

- If the proposal has no effect on the level of poverty, what options might be identified to produce a positive effect?

The 'target groups' were specified as: the unemployed, especially the long-term unemployed; children, especially those living in large 
families; single-adult households and households headed by someone working in the home; lone parents; people with disabilities; older people, in particular households headed by a retired person; members of the Traveller community; the homeless; and ethnic minorities. Additional explanation was also provided in relation to 'inequalities which may lead to poverty', where it was noted that such inequalities could arise in the context of age, gender, disability, belonging to an ethnic minority (including membership of the Traveller community) or sexual orientation. These target groups and 'inequalities which may lead to poverty' were broadly in line with seven (family status, age, gender, disability, race, membership of the Traveller community, sexual orientation) of the nine equality grounds, but did not include civil status or religion. As the poverty target groups were mainly based on groups identified as being at risk of poverty from household surveys, they did not include other people considered vulnerable, such as young people leaving care or people living in institutions.

The guidelines included a number of 'worked examples' provided by departments to demonstrate how poverty proofing could be carried out. In the pilot year, poverty proofing was only applied in civil service departments and was carried out by the civil servants who were developing the policy proposals. Poverty proofing was to be reviewed and revised, if deemed necessary, after a year of operation.

\section{Review and revision}

A formal review of poverty proofing was commissioned by the Department of Social, Community and Family Affairs from the National Economic and Social Council (NESC), which reported in 2001. Prior to that, Johnston \& O'Brien (2000) of the Combat Poverty Agency had undertaken an assessment of the NAPS in which they considered the initial application of poverty proofing. The NAPS was also formally reviewed by Goodbody Economic Consultants in 2001 and they made a brief reference to poverty proofing on the basis of the NESC review.

The NESC review included a discussion on the meaning of 'proofing', where it was deduced that there are two understandings of the term: that of 'sensitising' individuals involved in policy formation to the objectives of the NAPS in reducing poverty, and that of assessing policies for their impact on poverty. NESC concluded that poverty proofing was successful in 'sensitising' individuals to poverty 
reduction objectives (NESC, 2001, p. 60), with the Office for Social Inclusion (2006, p. 25) noting that:

There is little doubt that the introduction of the NAPS and the $\mathrm{NAP} /$ inclusion processes and their associated institutional and reporting structures has resulted in an increased awareness of social inclusion and anti-poverty issues in government departments generally.

While a high level of formal compliance with the poverty proofing procedures was noted, NESC considered that poverty proofing did not significantly influence policymaking (NESC, 2001, p. 59). Likewise, a respondent to the Johnston \& O'Brien assessment in 2000 (p. 67) stated that:

The poverty proofing process has failed to make its presence felt in any tangible way. Indications to date are that the process is only being applied to policies that are in themselves designed to have an impact on poverty. However, the point of the process was to [poverty] proof policies that might not have an obvious impact on poverty. Documentation... from Departments stating that 'the impact on those in poverty would be positive' is not a clear indication [of poverty proofing] as required by the Cabinet Handbook.

Even though the reviews remarked on these somewhat positive aspects of poverty proofing - a greater awareness of poverty by 'sensitising' officials and a level of formal compliance with the procedures - the majority of the findings from the reviews identified areas for improvement. There was an identified need for more rigorous assessment in undertaking poverty proofing, and this required addressing data deficiencies and compiling indicators by which progress could be measured. At the time, most of the poverty data were sourced from the Living in Ireland Survey undertaken by the Economic and Social Research Institute (ESRI). As it took at least two years to collect and analyse the data, the survey was out of date by the time it was published. In addition, the fact that it was only available at national level limited its usefulness by departmental officials tasked with carrying out poverty proofing. There were calls for greater use of administrative data as well as the compilation of statistics available at a local authority level. 
In addition to the identified need for more quantitative data to assist in the poverty proofing of policies, there was also a case for more qualitative data, both to provide information on groups at risk of poverty who were not captured by the survey data, and also to understand better the nature and experience of poverty.

For some, the lack of transparency in the poverty proofing process was an issue. For example, the community and voluntary sector called for poverty proofing assessments to be publicly available. In a number of areas the proofing of policies was published, most notably in relation to the annual budget. These annual budget proofing exercises were undertaken by the then Department of Social, Community and Family Affairs, which poverty proofed the social welfare budget, and the Department of Finance, which carried out a poverty proofing exercise on the income tax proposals. As stated in the NESC review (2001, p. 38), these poverty proofing exercises were welcomed by the social partners, but were criticised as an inadequate assessment of the impact of the budget on people in poverty. The criticisms, by the community and voluntary sector in particular, centred on the lack of an integrated budget proofing exercise where "what is important is the balance of the entire Budget package rather than discrete elements of the Budget' (p. 41). Departmental officials countered this argument by contending that 'the income tax and social welfare payment systems are addressing different constituencies and in that sense are parallel rather than directly interacting systems' (p. 41). Departmental officials also pointed out that there are criteria other than poverty which are taken into account when designing the budget, 'such as economic efficiency, rewarding effort and enterprise and risk taking, removing market distortions, controlling inflation and encouraging capital accumulation, all of which improve economic welfare greatly' (Department of Finance, 2000, Annex C).

The Combat Poverty Agency carried out and published assessments of the annual budgets with particular reference to the NAPS from 1998 onwards until its closure in 2009. These assessments, in general, tended to highlight: (a) the proportion of budget spend on povertyrelated measures, (b) the balance of spend between social welfare and tax measures in the budget, (c) the impact of the budgetary measures across the income distribution and (d) the impact on different family types. The analysis was limited to the annual tax and welfare budgetary changes and did not take account of the majority of government spend as set out in the departmental estimates. The ESRI too has undertaken annual assessments of the distributional impact of the 
budget..$^{1}$ Most of these assessments used the ESRI's microsimulation model SWITCH to analyse the distributional impact of the budget on various groups across the income distribution or in relation to different family types and socio-economic groups. These analyses have become more sophisticated over time so that one could argue that the technical ability is now available to proof budget proposals for their impact on poverty (ex ante) and to subsequently assess the actual impact on the measures taken (ex post). Whether the technical competence to undertake poverty proofing has led to the implementation of proposals to reduce poverty is a moot point as other factors are often put forward where this has not been the case, such as the availability of resources, the time available to undertake a comprehensive proofing exercise in advance of the budget, the other factors to improve economic welfare referred to above, as well as other political priorities.

A particular consideration at the time of the early reviews was how to develop a more integrated system of proofing, including, for example, poverty, gender and equality, and possibly rural and environmental issues as a more encompassing tool for policy proofing, rather than carrying out a number of parallel exercises. A number of groups and studies considered these issues (e.g. Combat Poverty Agency \& Equality Authority, 2003; Mullally \& Smith, 2000; National Economic and Social Forum, 1997) but found certain limitations to the development of such an integrated system, such as the need for an explicit understanding of some of the terms, the availability of data and indicators, and a requirement for integrated guidelines and the training of officials. In some cases there were seen to be conflicting objectives in relation to the priority afforded to the impacts of particular policies or programmes on some groups. The NESC review (2001, p. 58) concluded that an integrated process of policy proofing should be developed when the existing parallel processes were fully operational, and should incorporate a screening mechanism and greater coordination of guidelines and advisory functions.

On the basis of the NESC 2001 review, Goodbody Economic Consultants (2001, p. 85), in their review of the NAPS, recommended that an Office for Social Inclusion (an upgraded NAPS Unit) be established in the Department of Social, Community and Family Affairs and that it should be resourced to drive the proofing process, among other things. Goodbody recommended that to ensure poverty

${ }^{1}$ See www.esri.ie/research/taxation-welfare-and-pensions 
proofing was fully operationalised in all government departments, there would be a need to establish new guidelines, address data deficiencies, develop indicators, undertake some major assessments to illustrate the benefits of the process, establish cross-departmental teams, and provide resources and training. They also suggested extending poverty proofing outside of government departments to other state agencies and to have greater coordination with other proofing procedures, such as rural and gender proofing. Some of these recommendations were introduced over time; for example, the Office for Social Inclusion was established in 2002, and data on poverty were improved with the introduction of the EU Survey of Income and Living Conditions (EU-SILC), which was carried out by the CSO and was part of a Europe-wide survey. The development of social inclusion units and plans was extended to local government, with the Combat Poverty Agency supporting this process (Combat Poverty Agency, 2005).

At the time of the Goodbody review of the NAPS in 2001, Ireland was experiencing unprecedented growth. Over the period 1994 to 2000 , the proportion of the population in consistent poverty fell from 15.1 per cent to 6.2 per cent. The NAPS had been in place from 1997, and poverty proofing had been introduced in 1998. It is not possible to say to what impact, if any, the NAPS and poverty proofing had on this level of poverty reduction, other than to say that they raised awareness of the extent of the problem and the range of measures required to address it, as discussed earlier. Nevertheless, it was acknowledged in various documents that more needed to be done and a revised NAPS, Building an Inclusive Society, was published in 2002, building on the Goodbody review of the NAPS (Department of Social, Community and Family Affairs, 2002). This strategy undertook to reduce and ideally eliminate poverty in Ireland, set benchmarks for social welfare rates and focused on substantial poverty reduction for a variety of 'vulnerable groups', identified in this case as children and young people, women, older people, Travellers, people with disabilities, plus migrants and members of ethnic minority groups. There was also a strong statement about poverty proofing:

The National Office for Social Inclusion will be resourced to develop a more effective poverty proofing process and to ensure that it is appropriately operationalised in all relevant Government Departments... Rural and gender proofing procedures are also in place, and have a role to play in promoting social 
inclusion. Increased co-ordination of these proofing measures will be developed. (Department of Social, Community and Family Affairs, 2002, p. 25)

The Irish social inclusion process was boosted by an EU commitment to 'make a decisive impact on the eradication of poverty and social exclusion' by 2010 under the Lisbon Treaty (2000). This commitment was to be operationalised through an 'Open Method of Co-ordination' which required member states to submit National Action Plans Against Poverty and Social Exclusion (NAPs/inclusion) to the European Commission. The first plans, covering the period 2001-3, were submitted in 2001, setting out their strategies, actions and institutional arrangements. Subsequent plans were submitted in 2003, covering the period 2003-5, and in 2006, for 2006-8 (Office for Social Inclusion, 2006, pp. 19-20).

In 2005 the Office for Social Inclusion undertook a further review of poverty proofing (Office for Social Inclusion, 2006). It noted a key finding of the NESC review that while there was a high level of formal compliance with the poverty proofing procedure, it did not result in any significant influence on policymaking. It also assessed the extent to which statements of strategy and annual business plans, expenditure reviews and government memoranda had been poverty proofed. In their examination the Office for Social Inclusion found that no statements of strategy or annual business plans had been poverty proofed, but that poverty proofing was an integral part of expenditure reviews carried out by its department, Social and Family Affairs, and was undertaken before decisions were made on what actions to take. In relation to government memoranda, it found that the impact on poverty was given 'just a cursory mention' (Office for Social Inclusion, 2006, p. 26).

On the basis of its review, which involved documentary examination and a consultation process, the Office for Social Inclusion recommended the introduction of poverty impact assessment to address the deficiencies which had been identified in the various reviews of poverty proofing. It proposed a change in the terminology from poverty proofing to poverty impact assessment because it said that the term 'proofing' had been confusing for some people, by suggesting that the process should take place after a decision had been made and then to 'proof the policy' as an 'add-on' rather than as an integral part of the process. For this reason it suggested that the process should be called poverty impact assessment instead, 
contending that 'this change of name will help to clarify what the process is trying to achieve in that it is immediately obvious from the title' (Office for Social Inclusion, 2006, p. 36). The office also argued that it brought 'poverty proofing' more in line with similar mechanisms such as environmental impact assessment and regulatory impact assessment, reflecting international trends. A more significant point, however, was how the process was to be carried out.

The Office for Social Inclusion set out a two-stage, seven-step process for poverty impact assessment, which addressed a number of the concerns that had been raised in the earlier reviews. The first stage was a screening exercise, which was introduced in an effort to ensure that a full poverty impact assessment was only carried out on those policies and programmes where it was really required. Where the policy or expenditure was considered 'significant', or 'relevant' to the 'vulnerable groups' as identified in the National Action Plan against Poverty and Social Exclusion, a second-stage full poverty impact assessment would be carried out.

The second stage's seven steps were:

i. consultation;

ii. defining the policy aims and target groups;

iii. considering the available data and research;

iv. assessing the impacts on poverty and considering alternatives;

v. making a decision on the proposal and arranging monitoring;

vi. publishing the results; and

vii. returning a summary sheet to the social inclusion officer in the department.

There were a number of new features to this poverty impact assessment process which addressed earlier concerns. The community and voluntary sector, in particular, had been critical of the previous poverty proofing process because it was mainly an administrative exercise where those potentially impacted by a policy were not involved in its proofing. The new poverty impact assessment sought to address this by having consultation as its first step. On defining policy aims and target groups, and considering the available data and research, further material was provided, including a table of definitions and information on data sources, poverty measurement and indicators. The obligation to arrange monitoring and publish the results was a new requirement. The introduction of monitoring ensured the assessment of the impact of the policy or programme once 
it was introduced against specified indicators. The requirement to publish the results aimed to improve the transparency of the process, which had been requested by a number of commentators.

This revision of poverty proofing went hand in hand with other institutional developments, including strengthening the position of the Office for Social Inclusion and enhancing the role of social inclusion officers located in government departments. The new poverty impact assessment process was to be applied at regional and local level, as well as national level, which meant that the process was to be undertaken by state agencies and local authorities.

Another dimension from the reviews of poverty proofing was the consideration of a more integrated proofing tool. An integrated proofing template was piloted by an Equality Proofing Working Group in 2004, bringing together gender, poverty and equality. One of the conclusions from this work was that there should continue to be a focus on equality in poverty proofing. Thus, the Office for Social Inclusion decided to retain the requirement in the poverty impact assessment process for policymakers to consider whether or not the policy or programme would address inequalities which lead to poverty, but it decided not to introduce a fully integrated proofing mechanism (Office for Social Inclusion, 2006, p. 47). Guidelines on the poverty impact assessment process were published in March 2008 (Office for Social Inclusion, 2008).

The National Action Plan for Social Inclusion 2007-2016 was published in 2007. This plan took a life cycle approach, setting out high-level poverty-reduction goals for children, people of working age and older people, as well as for people with disabilities and communities with homelessness, carers, Travellers and migrants specifically mentioned. The plan also adopted a developmental welfare state framework, specifying income-support actions, services to be provided and innovative measures. The plan was unusual in setting out a ten-year framework. It specified a range of institutional structures to 'underpin the implementation, monitoring and ongoing development of the Government's social inclusion agenda' (Government of Ireland, 2007, p. 77). Reference was made to the poverty impact assessment guidelines, which had been rolled out to government departments on a pilot basis and which were due to be issued to all areas of government, including local government. An important element was the recognition of the need for a training programme to assist policymakers in carrying out poverty impact assessment. 


\section{Current position}

The economic crash, subsequently referred to as the great recession, hit Ireland in late 2008. As the state was adjusting to a series of financial crises, major reforms and cutbacks took place. These included the closure of the Combat Poverty Agency in 2009 and absorption of part of its remit into the Social Inclusion Unit of the Department of Social Protection (previously Social, [Community] and Family Affairs). There were also substantial reductions, estimated at 48 per cent, in many funding programmes supporting disadvantaged groups (Harvey, 2012). Consistent poverty increased, and there was a large rise in levels of deprivation (NESC, 2013). An analysis by the ESRI of budgets over the 2009-16 period showed that the greatest policy-induced losses were for the top income group and the lowest income group (Callan et al., 2015).

It is difficult to find evidence of any poverty impact assessment during the great recession, although the main social welfare rates were broadly maintained during this period. There were, however, developments at European and national level in social inclusion policy. In June 2010 the European Council adopted Europe 2020: A Strategy for Smart, Sustainable Growth, which included a commitment to lift 20 million people out of poverty by 2020 . At national level the government undertook a review of the national poverty target in 2012 and, based on the review, set a national social target for poverty reduction. An annual social inclusion monitor is produced as an official report of progress towards the target. In 2016 the Department of Social Protection published the Updated National Action Plan for Social Inclusion 2015-2017 (Department of Social Protection, 2016).

While the current poverty reduction plans do not contain a reference to poverty proofing or poverty impact assessment, in March 2013 the Department of Social Protection published a social impact assessment of the main welfare measures and direct tax measures in Budget 2013. It defined social impact assessment as:

An evidence-based methodology to estimate the likely distributive effects of policy proposals on income and social inequalities, which builds on the practice of poverty impact assessment. (Department of Social Protection, 2013, p. 1)

A number of reasons were given for this transition from poverty impact assessment to social impact assessment: it is used as a tool in 
Europe for mainstreaming social inclusion in public policy; it extends the poverty impact assessment to other dimensions of social inequality such as age and gender; and it is thought to 'facilitate greater policy coordination in the social sphere' (Department of Social Protection, 2013, p. 2). These social impact assessments have been carried out by the Department of Social Protection on the budget annually since 2013. The ESRI also undertakes an annual assessment of the distributional impact of the tax and welfare policies in the budget. Both of these budget assessments use the tax/welfare microsimulation model SWITCH. This approach has been developed by the Irish Government Economic and Evaluation Service, which has proposed a social impact assessment framework that not only takes account of these existing practices but has broadened the scope of the exercise to take account of expenditure on public services, and to compare the distributional impact of changes to various types of public services and the implications for household incomes (Lawless \& Reilly, 2016).

\section{Meeting the government commitment - What should be done?}

The experience of poverty proofing over the last nineteen years has undoubtedly raised awareness across government and at local authority level of the need to design and implement policies to tackle poverty. It has been implemented rather sporadically, being led mainly by the Department of Social Protection, with contributions from the Department of Education \& Skills, the Department of Housing, Planning, Community and Local Government, and the Department of Finance. It has been the subject of a number of reviews, which have pointed out weaknesses and sought to develop and improve the methodology. Its iterations have ranged from poverty proofing to poverty impact assessment to social impact assessment. It cannot be said definitively that poverty proofing has resulted in poverty reduction but it has certainly 'sensitised' policymakers across government to the need to take into consideration the impact of policies and programmes on people living in poverty.

In that context, the current commitment in the programme for government should be welcomed. A key question, however, in meeting the commitment in the programme for government is whether the process of budget and policy proofing as a means of advancing equality, reducing poverty and strengthening economic and social rights could be integrated in some way. The social impact assessment framework provides a template in which such an integrated proofing 
process could be developed, with the added value of having the potential to maximise available resources. A number of issues would need to be addressed in order to take such an approach forward. For example, there would need to be clarity on the 'at risk' groups, which are defined differently in terms of being at risk of poverty or vulnerable in poverty impact assessments and in relation to equality grounds in the equality legislation. A possible way forward would be to name socio-economic status as a tenth equality ground, thus capturing the poverty aspect plus naming the economic and social rights dimension.

Drawing on the experience of poverty proofing, it is evident that a number of other elements need to be considered in taking forward a more integrated approach. Consultation with the people and groups affected as part of the process is important. As many of these groups are vulnerable, and at risk of exclusion, it will be necessary to put in place resources to build their capacity to take part in such consultations. Likewise, for public servants undertaking the impact assessment, support and training have been identified as being requirements. At local level the recently established local community development committees could potentially have a role in social impact assessment at local level, but would need to be adequately resourced to do so. The need for good-quality quantitative and qualitative data has been highlighted throughout as being a central component of impact assessment, and our sources of data continue to improve. The coordination of an administrative data centre by the CSO should facilitate those undertaking social impact assessments. Finally, there is a need for a body to have some oversight of the application of social impact assessment, in terms of both its operation and outcomes. A body such as NESC, with its cross-societal representation and policy focus, would seem to be well placed to undertake such a role. The building blocks are available to meet the commitment of developing the process of budget and policy proofing as a means of advancing equality, reducing poverty, and strengthening economic and social rights. What remains to be done is to construct the infrastructure in which to place these blocks to make such an integrated social impact assessment operational.

\section{References}

Callan, T., Colgan, B., Logue, C., Savage, M., \& Walsh, J. R. (2015). Distributional impact of tax, welfare and public service pay policies: Budget 
2016 and Budgets 2009-2016 [Special Article]. Retrieved from www.esri.ie [22 March 2017].

Combat Poverty Agency. (2005). Developing a local anti-poverty strategy: A guide. Dublin: Combat Poverty Agency.

Combat Poverty Agency \& Equality Authority. (2003). Poverty and inequality: Applying an equality dimension to poverty proofing. Dublin: Combat Poverty Agency \& Equality Authority.

Department of Finance. (2000). Budget 2001 documents: Summary of budget measures: Annex C. Retrieved from www.budget.gov.ie/Budgets/ 2001/AnnexC.aspx [21 March 2017].

Department of Social, Community and Family Affairs. (1998). Policy proofing in the context of the National Anti-Poverty Strategy. Unpublished paper, NAPS Unit.

Department of Social, Community and Family Affairs. (2002). Building an inclusive society. Dublin: Department of Social, Community and Family Affairs.

Department of Social Protection. (2013). Social impact assessment of the main welfare and direct tax measures in Budget 2013. Retrieved from www.welfare.ie [22 March 2017].

Department of Social Protection. (2016). Updated national action plan for social inclusion 2015-2017. Retrieved from www.welfare.ie [22 March 2017].

Department of the Taoiseach. (2005). Report on the introduction of regulatory impact analysis. Dublin: Department of the Taoiseach.

Goggins, I., \& Lauder, L. (2008). Review of the operation of regulatory impact analysis. Dublin: Department of the Taoiseach.

Goodbody Economic Consultants. (2001). Review of the National Anti-Poverty Strategy: Framework document. Dublin: Goodbody Economic Consultants.

Government of Ireland. (1997). Sharing in progress. Dublin: The Stationery Office.

Government of Ireland. (2007). National action plan for social inclusion 2007-2016. Dublin: The Stationery Office.

Government of Ireland. (2016). A programme for a partnership government. Retrieved from www.taoiseach.gov.ie [15 March 2017].

Harvey, H. (2012). Downsizing the community sector: Changes in employment and services in the voluntary and community sector in Ireland, 2008-2012. Dublin: Irish Congress of Trade Unions.

Johnston, H., \& O'Brien, T. (2000). Planning for a more inclusive society: An initial assessment of the National Anti-Poverty Strategy. Dublin: Combat Poverty Agency.

Lawless, J., \& Reilly, D. (2016). Social impact assessment framework [Staff Paper]. Dublin: Irish Government Economic and Evaluation Service.

Mullally, S., \& Smith, O. (2000). Partnership 2000 Working Group report on equality proofing. Dublin: The Stationery Office. 
National Economic and Social Forum. (1997). Partnership 2000: Development of the equality provisions. Dublin: National Economic and Social Forum.

NESC. (2001). Review of the poverty proofing process. Dublin: NESC.

NESC. (2013). The social dimensions of the crisis: The evidence and its implications. Dublin: NESC.

Office for Social Inclusion. (2006). Review of poverty proofing. Retrieved from www.socialinclusion.ie [15 March 2017].

Office for Social Inclusion. (2008). Guidelines for poverty impact assessment. Retrieved from www.socialinclusion.ie [15 March 2017]. 